\title{
CAMBRIDGE
}

\section{Fantastic Titles in Robotics!}

\section{NIST Handbook}

\section{of Mathematical Functions}

Edited by Frank W. J. Olver,

Daniel W. Lozier, Ronald F. Boisvert, and Charles W. Clark

"The NIST Handbook is a handsome product, with for convenience, one might be inclined to place it on a stand, as with an unabridged dictionary. The book contains numerous graphics, almost all in color. References and cross references to books and articles abound. Applications to both the mathematical and physical sciences are indicated. The NIST Handbook is indeed a monumental achievement, and the many, many individuals who participated in its creation and dissemination are to be congratulated."

- SIAM News

\$99.00: 1 Hardback, 1 CD-ROM: 978-0-521-19225-5: 968 pp. \$50.00: 1 Paperback, 1 CD-ROM: 978-0-521-14063-8 large pages and large type. The book is quite heavy;

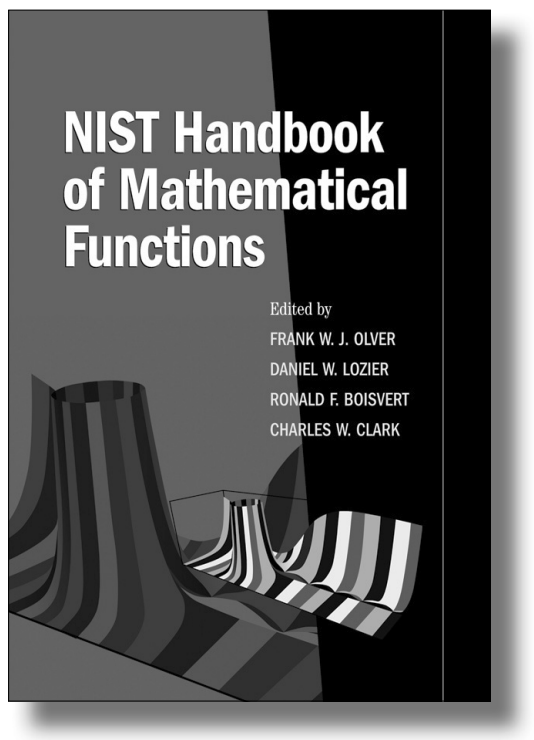

\section{Sparse Image}

and Signal Processing

Wavelets, Curvelets, Morphological Diversity

Jean-Luc Starck, Fionn Murtagh, and JALAL M. FADILI

This book presents the state of the art in sparse and multiscale image and signal processing, covering linear multiscale transforms, such as wavelet, ridgelet, or curvelet transforms, and non-linear multiscale transforms based on the median and mathematical morphology operators. Matlab and IDL code accompany these methods and applications to reproduce the experiments and illustrate the reasoning and methodology of the research available for download at the associated Web site.

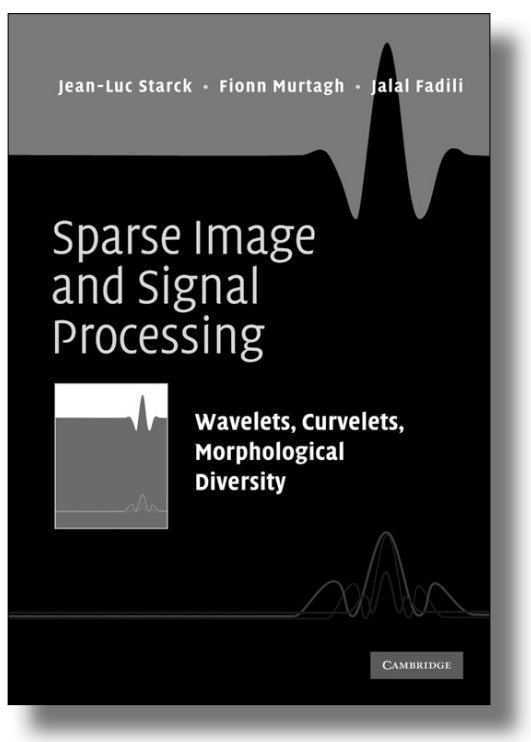

\$70.00: Hardback: 978-0-521-11913-9: 336 pp.

Prices subject to change. 


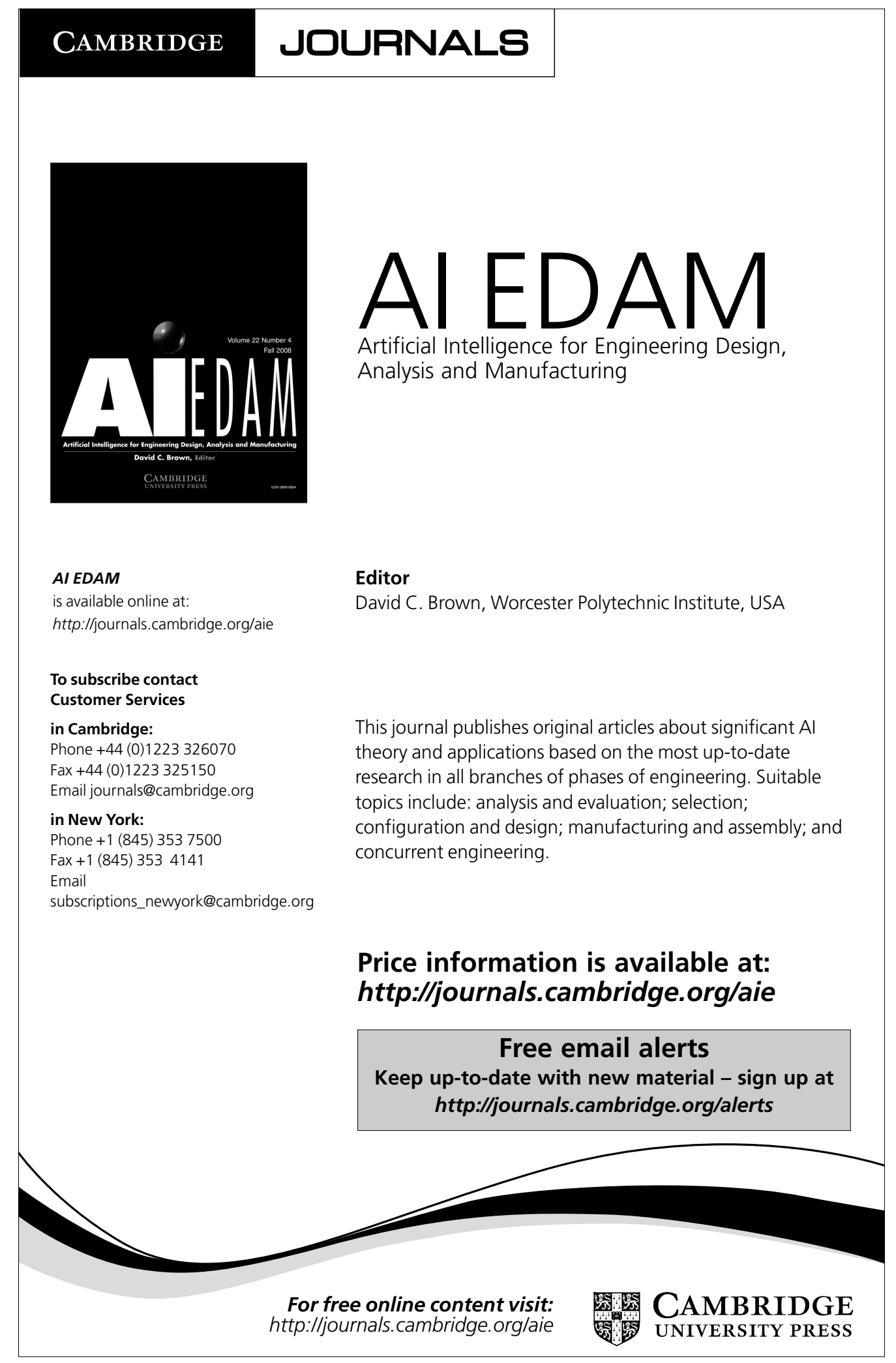




\section{Combinatorics, Probability and Computing}

\section{Editor-in-Chief}

Béla Bollobás, DPMMS, Cambridge, UK; University of Memphis, USA

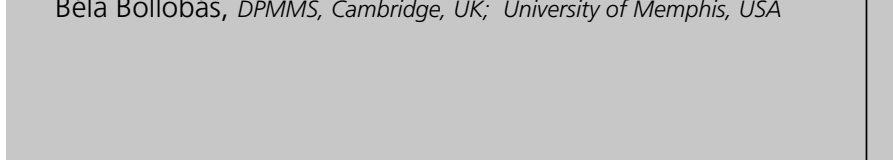

Published bimonthly, Combinatorics, Probability \& Computing is devoted to the three areas of combinatorics, probability theory and theoretical computer science. Topics covered include classical and algebraic graph theory, extremal set theory, matroid theory, probabilistic methods and random combinatorial structures; combinatorial probability and limit theorems for random combinatorial structures; the theory of algorithms (including complexity theory), randomised algorithms, probabilistic analysis of algorithms, computational learning theory and optimisation.

\section{Price information}

is available at: http://journals.cambridge.org/cpc

\section{Free email alerts}

Keep up-to-date with new material - sign up at http://journals.cambridge.org/cpc-alerts

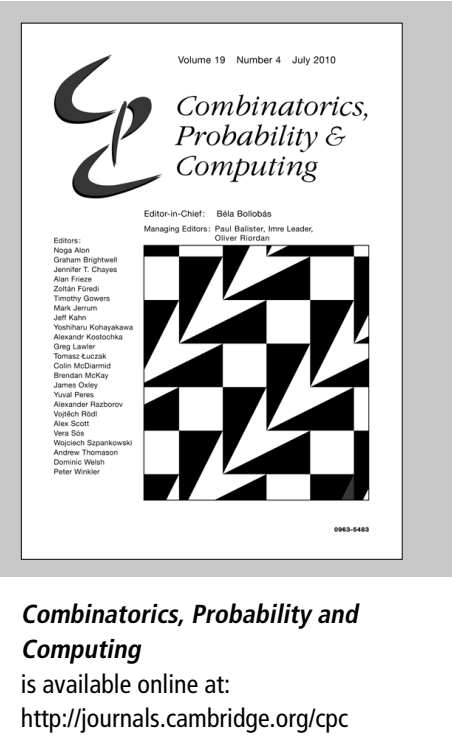

To subscribe contact Customer Services

\section{in Cambridge:}

Phone +44 (0)1223 326070

Fax +44(0)1223 325150

Email journals@cambridge.org

\section{in New York:}

Phone +1 (845) 3537500

Fax +1 (845) 3534141

Email

subscriptions_newyork@cambridge.org 


\section{Journal of Functional Programming}

\section{Editors-in-Chief}

Matthias Felleisen, Northeastern University, USA

Xavier Leroy, INRIA Rocquencourt, France

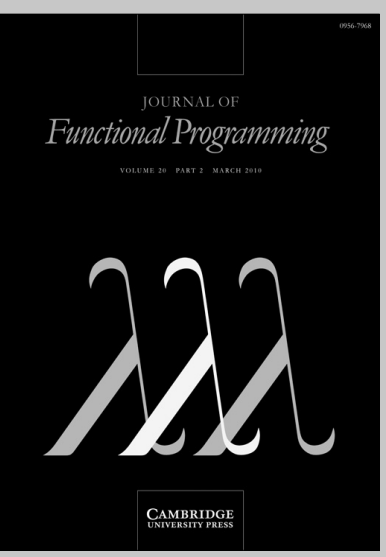

The Journal of Functional Programming is the only journal devoted solely to the design, implementation, and application of functional programming languages, spanning the range from mathematical theory to industrial practice. Topics covered include functional languages and extensions, implementation techniques, reasoning and proof, program transformation and synthesis, type systems, type theory, language-based security, memory management, parallelism and applications. The journal is of interest to computer scientists, software engineers, programming language researchers and mathematicians interested in the logical foundations of programming.

\section{Price information}

is available at: http://journals.cambridge.org/jfp

\section{Free email alerts}

Keep up-to-date with new material - sign up at http://journals.cambridge.org/jfp-alerts

Journal of Functional

Programming

is available online at: http://journals.cambridge.org/jfp

To subscribe contact Customer Services

\section{in Cambridge:}

Phone $+44(0) 1223326070$

Fax $+44(0) 1223325150$

Email journals@cambridge.org

\section{in New York:}

Phone +1 (845) 3537500

Fax +1 (845) 3534141

Email

subscriptions_newyork@cambridge.org 


\section{The Knowledge Engineering Review}

\section{Editors-in-Chief}

Peter McBurney, University of Liverpool, UK

Simon Parsons, Brooklyn College, City University of New York, USA

The Knowledge Engineering Review is committed to the development of the field of artificial intelligence and the clarification and dissemination of its methods and concepts. KER publishes analyses - high quality surveys providing balanced but critical presentations of the primary concepts in an area; technical tutorials - detailed introductions to an area; application and country surveys commentaries and debates; book reviews; and a popular 'from the journals' section, providing the contents of current journals in theoretical and applied artificial intelligence.

\section{Price information}

is available at: http://journals.cambridge.org/ker

\section{Free email alerts}

Keep up-to-date with new material - sign up at http://journals.cambridge.org/ker-alerts

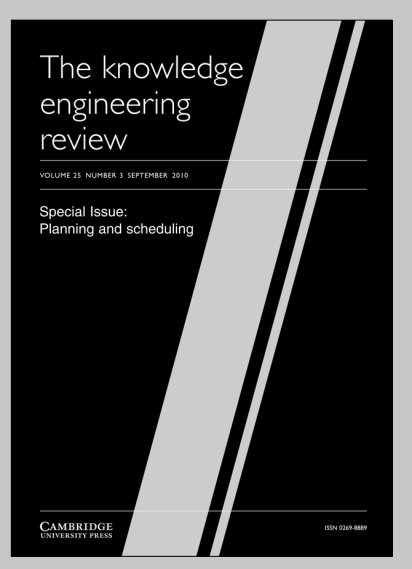

The Knowledge Engineering Review

is available online at: http://journals.cambridge.org/ker

To subscribe contact Customer Services

\section{in Cambridge:}

Phone $+44(0) 1223326070$

Fax $+44(0) 1223325150$

Email journals@cambridge.org

\section{in New York:}

Phone +1 (845) 3537500

Fax +1 (845) 3534141

Email

subscriptions_newyork@cambridge.org 


\section{Mathematical Structures in Computer Science}

\section{Editor-in-Chief}

G. Longo, CNRS and Ecole Normale Supérieure, Paris, France

Mathematical Structures in Computer Science is a journal of theoretical computer science which focuses on the application of ideas from the structural side of mathematics and mathematical logic to computer science. The journal aims to bridge the gap between theoretical contributions and software design, publishing original papers of a high standard and broad surveys with original perspectives in all areas of computing, provided that ideas or results from logic, algebra, geometry, category theory or other areas of logic and mathematics form a basis for the work.

\section{Price information}

is available at: http://journals.cambridge.org/msc

\section{Free email alerts}

Keep up-to-date with new material - sign up at http://journals.cambridge.org/msc-alerts

\section{in Cambridge:}

Phone +44 (0)1223 326070

Fax +44 (0)1223 325150

Email journals@cambridge.org

\section{in New York:}

Phone +1 (845) 3537500

Fax +1 (845) 3534141

Email

subscriptions_newyork@cambridge.org http://journals.cambridge.org/msc 


\title{
Natural Language Engineering
}

\author{
Executive Editor \\ Ruslan Mitkov, University of Wolverhampton, UK
}

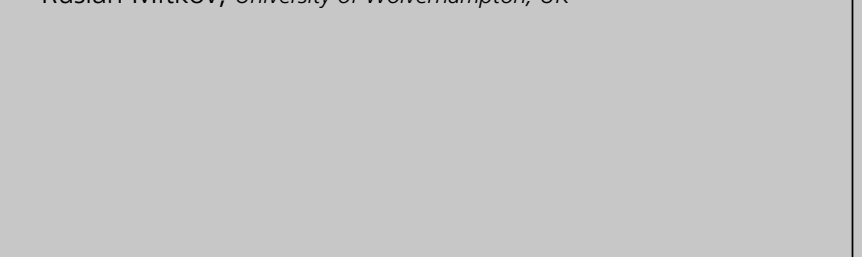

Natural Language Engineering meets the needs of professionals and researchers working in all areas of computerised language processing, whether from the perspective of theoretical or descriptive linguistics, lexicology, computer science or engineering. Its aim is to bridge the gap between traditional computational linguistics research and the implementation of practical applications with potential real-world use. The journal publishes research articles on a broad range of topics, an industry-watch column and book reviews. JNLE now includes surveys, as well as squibs discussing specific problems.

\section{Price information}

is available at: http://journals.cambridge.org/nle

\section{Free email alerts}

Keep up-to-date with new material - sign up at http://journals.cambridge.org/nle-alerts

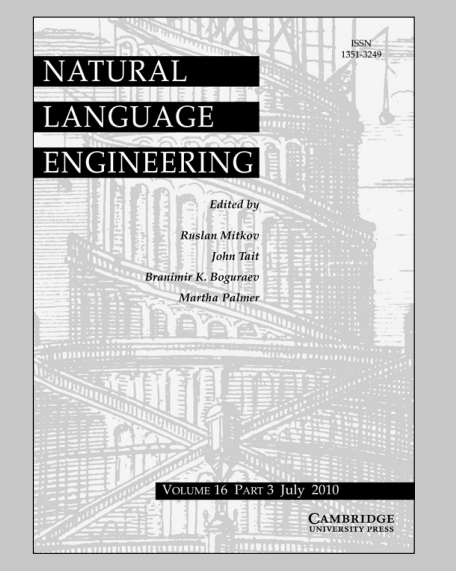

Natural Language Engineering is available online at: http://journals.cambridge.org/nle

To subscribe contact Customer Services

\section{in Cambridge:}

Phone +44 (0)1223 326070

Fax +44(0)1223 325150

Email journals@cambridge.org

\section{in New York:}

Phone +1 (845) 3537500

Fax +1 (845) 3534141

Email

subscriptions_newyork@cambridge.org 


\section{Instructions for contributors}

Robotica aims to be an outlet for publication of original papers of the highest quality in the field of Robotics and closely related areas. This includes: novel robotic mechanism and actuator design; robot kinematics, dynamics and control; computer vision; sensor fusion; teleoperation and haptic interfaces; robot motion planning; and artificial intelligence. In addition, papers that apply techniques from Robotics to other fields are also welcome. Examples include dynamics and control models applied to biological systems, the description of implementations of robots in factories, service and agricultural settings, and general mechatronic design. Works may be theoretical, computational or experimental, or some combination. Both short papers (rapid communications), and longer archival papers are welcome. Proposals for special issues on topics of current interest are welcome, and can be submitted via email to the editor.

Authors are urged to ensure that their papers are written clearly and attractively, in order that their work will be readily accessible to readers. Manuscripts must be written in English. Robotica employs a rigourous peer-review process whereby all submitted manuscripts are sent to recognized experts in their subjects for evaluation. The Editor's decision on the suitability of a manuscript for publication is final. Manuscripts, whether accepted or rejected, will not be returned to authors.

\section{Submission of manuscripts}

Manuscripts for consideration by Robotica should be submitted electronically, using the Manuscript Central System, via http://mc.manuscriptcentral.com/cup/robotica. This system will allow authors to benefit from faster review and earlier, online publication. The system will accept PDF files; most other files types will be automatically converted directly into PDF. Source files are required for any paper accepted for publication. Authors who are unable to submit online should contact the Editorial Office (gregc@jhu.edu) for assistance.

Submission of a paper is taken to imply that it has not been previously published and that it is not being considered for publication elsewhere. Upon acceptance of a paper, the author will be asked to transfer copyright to the publisher. Authors are responsible for obtaining written permission from the copyright owners to reprint any previously published material included in their article.

\section{Layout of manuscripts}

Text should be double spaced throughout, on one side of the paper, allowing generous margins on all sides of the paper. Please avoid footnotes if possible. Papers should begin with an abstract of not more than 100 words and should end with a brief concluding section. The title and section headings should be concise and descriptive. All measurements should be given in SI units. On acceptance of a manuscript, authors are asked to send the electronic source file of the final version together with a PDF copy produced using the same file. The publisher reserves the right to typeset material by conventional means if an author's file proves unsatisfactory.

\section{Illustrations}

Figures should be composed to occupy a single column $(80 \mathrm{~mm})$ or two columns $(166 \mathrm{~mm})$ after reduction. The preferred format for figure files is .eps or .tiff at resolution $1200 \mathrm{dpi}$ for lines, $600 \mathrm{dpi}$ for greyscale and $300 \mathrm{dpi}$ for colour (which preferably should also be in CMYK - cyan magenta yellow black - format). However, most standard image formats such as pct, ppm, png, psd, Word, ppt, CorelDraw, ChemDraw, AutoCAD can also be used, but not customized output of software not designed for publishing purposes such as Matlab, nor PDF. Figures to be printed in black and white must be submitted as black and white files.

Figures should be numbered consecutively, with Arabic numerals, have descriptive captions, and be mentioned in the text. A list of captions should be attached separately, and as far as possible, information relating to a figure should be placed in the caption rather than on the figure. Each figure should be clearly numbered. Photographs should be the same size as they will appear in the journal and should be selected to fit neatly into one column $(80 \mathrm{~mm})$ or two columns (166 mm). Photographs should be clearly identified and numbered as for line drawings.

\section{Tables}

Tables should be presented on separate sheets. A descriptive title should be given to each table. If possible, very wide tables should be avoided. Tables should be numbered consecutively in Roman numerals. Exceptionally lengthy tables may be summarized for publication with a note that fuller details can be obtained from the authors.

\section{Equations}

Mathematical equations should be typewritten, with subscripts and superscripts clearly indicated. All mathematical symbols will be set in italics unless otherwise indicated: symbols or letters to be set in Roman (upright) type should be marked clearly.

\section{References}

In the text, references are indicated by superior Arabic numbers (without brackets), and should be confined to published work that is directly pertinent. References should be listed at the end of the paper in numerical order. Authors' initials should precede their names: cited article titles should be quoted in full, enclosed in quotation marks; and abbreviations of journal names should follow the style of Chemical Abstracts or Physical Abstracts, and be underlined for italics:

P.W. Anderson, "More is different" Science 177, 393-399 (1972); C.V. Negoita, Fuzzy Systems (Abacus Press. Tunbridge Wells, UK, 1980).

Citations such as 'personal communication', 'unpublished work', etc., are not acceptable as numbered references but can be included in parenthesis in the text. Do not use summaries as references.

\section{Proof Reading}

The corresponding author will receive PDF copies of page proofs for final proofreading. Only typographical or factual errors may be changed at proof stage. The publisher reserves the right to charge authors for correction of non-typographical errors. Authors are requested to return proofs within 48 hours by airmail. No page charge is made.

\section{Offprints}

No paper offprints are provided, but the corresponding author will be sent the pdf of the published article. Print offprints may be purchased at extra cost at proof stage.

\section{(C) CAMBRIDGE UNIVERSITY PRESS 2011}

Cambridge University Press

The Edinburgh Building, Cambridge CB2 8RU, United Kingdom

32 Avenue of the Americas, New York, NY 10013-2473, USA

477 Williamstown Road, Port Melbourne, VIC 3207, Australia

Ruiz de Alarcón 13, 28014, Madrid, Spain

Dock House, The Waterfront, Cape Town 8001, South Africa 


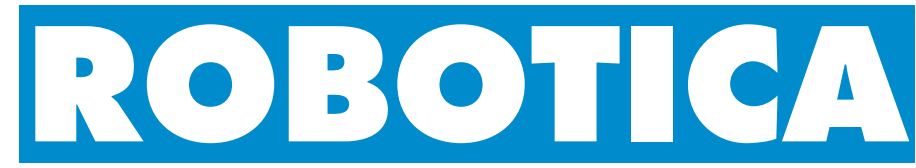

\section{Volume 29 Part 1 January 2011}

\section{Special Issue}

Robotic Self-X Systems

Editorial, Amor A. Menezes and Pierre T. Kabamba

Self-detection in robots: a method based on detecting temporal contingencies, Alexander Stoytchev

A low-cost approach for self-calibration of climbing robots, Mahmoud Tavakoli, Lino Marques and Aníbal T. de Almeida

Robust and reversible execution of self-reconfiguration sequences,

Ulrik Schultz, Mirko Bordignon and Kasper Stoy

Efficient constant-velocity reconfiguration of crystalline robots, Greg Aloupis, Sébastien Collette, Mirela Damian, Erik D. Demaine, Robin Flatland, Stefan Langerman, Joseph O'Rourke, Val Pinciu, Suneeta Ramaswami, Vera Sacristán and Stefanie Wuhrer

A characterization of the reconfiguration space of self-reconfiguring robotic systems, Tom Larkworthy and Subramanian Ramamoorthy

Planning to fold multiple objects from a single self-folding sheet, Byoungkwon An, Nadia Benbernou, Erik D. Demaine and Daniela Rus

A general stiffness model for programmable matter and modular robotic structures, Paul J. White, Shai Revzen, Chris E. Thorne and Mark Yim

The von Neumann threshold of self-reproducing systems: theory and application, Pierre T. Kabamba, Patrick D. Owens and A. Galip Ulsoy

A stochastic self-replicating robot capable of hierarchical assembly,

Georgios Kaloutsakis and Gregory S. Chirikjian

A self-replicating programmable constructor in a kinematic simulation environment, William M Stevens

RepRap - the replicating rapid prototyper, Rhys Jones, Patrick Haufe,

Edward Sells, Pejman Iravani, Vik Olliver, Chris Palmer and Adrian Bowyer

Robotica now accepts submissions via Manuscript Central

Go to http://mc.manuscriptcentral.com/cup/robotica

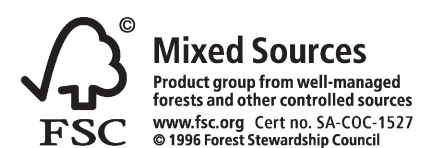

